\title{
Qualidade de kiwis minimamente processados e submetidos a tratamento com ácido ascórbico, ácido cítrico e cloreto de cálcio(1)
}

\author{
Ana Vânia Carvalho(2) e Luiz Carlos de Oliveira Lima(3)
}

\begin{abstract}
Resumo - Frutos e hortaliças minimamente processados devem apresentar atributos de conveniência e qualidade do produto fresco. O objetivo deste trabalho foi estudar o efeito do processamento mínimo de frutos tratados com soluções a $1 \%$ de ácido ascórbico, ácido cítrico e cloreto de cálcio, durante armazenamento refrigerado, na qualidade do kiwi (Actinidia deliciosa cv. Hayward). A perda de massa foi mínima durante o período de armazenamento. $\mathrm{O}$ ácido ascórbico fornecido pelo tratamento foi eficientemente absorvido pelos tecidos, mantendo os níveis de vitamina $\mathrm{C}$ cerca de $25 \%$ mais elevados nesses frutos do que nos demais tratamentos. A análise microbiológica detectou presença de bolores e leveduras e psicrotróficos, somente no tratamento com ácido cítrico, aos 8 e 10 dias, respectivamente. Não se detectaram coliformes totais e fecais e mesófilos, o que indica que o processamento foi realizado em boas condições higiênicas. Os kiwis minimamente processados e tratados com cloreto de cálcio apresentaram uma vida útil de dez dias. Nos demais tratamentos e no controle, esse tempo foi de seis dias.
\end{abstract}

Termos para indexação: Actinidia deliciosa, processamento, aditivos, análise microbiológica, armazenamento.

Quality of kiwis minimally processed and treated with ascorbic acid, citric acid and calcium chloride

Abstract - Minimally processed fruits and vegetables might present the same convenience and quality of fresh products. In this work, the influence of minimal processing of fruits treated with $1 \%$ solutions of ascorbic acid, citric acid and calcium chloride on the quality of kiwi (Actinidia deliciosa cv. Hayward), during refrigerated storage were investigated. Mass loss was minimal over the storage period. Ascorbic acid furnished by the treatment was effectively absorbed by tissues, keeping the vitamin C levels $25 \%$ higher in those fruits, than in other treatments. Microbiological analysis detected the presence of the group molds and yeasts and psychrotrophic in citric acid treatment, at 8 and 10 days, respectively. Total and faecal coliforms and mesophyles were not found, indicating that processing was performed under good hygienic conditions. Minimally processed and calcium chloride treated kiwis presented a ten-day shelflife. For other treatments and for control, shelflife was six days.

Index terms: Actinidia deliciosa, processing, additives, microbiological analysis, storage.

\section{Introdução}

No Brasil, o kiwi foi introduzido na década de 70 , pelo Instituto Agronômico (IAC), Campinas, SP, mas somente nos últimos 10 anos a cultura vem desper-

(1) Aceito para publicação em 5 de junho de 2001 .

Extraído da dissertação de mestrado apresentada pelo primeiro autor à Universidade Federal de Lavras (Ufla), Lavras, MG.

(2) Ufla, Dep. de Ciência dos Alimentos, Caixa Postal 37, CEP 37200-000 Lavras, MG. Bolsista da Capes. E-mail: anavania@fea.unicamp.br

(3) Ufla, Dep. de Ciência dos Alimentos. E-mail: lcolima@ufla.br tando um interesse crescente, em razão dos bons preços alcançados pelo fruto no mercado nacional, pelo potencial produtivo, baixo custo de produção, e, aos poucos problemas fitossanitários apresentados (Schuck, 1992). Destacam-se, como principais estados produtores, Minas Gerais, São Paulo, Santa Catarina, Paraná e Rio Grande do Sul.

O kiwi possui alto valor nutritivo, sendo rico principalmente em vitamina $\mathrm{C}$ e fibras, apresentando grande aceitação nos mercados consumidores. Porém, ao ser oferecido, por exemplo, como sobremesa ou lanche, deve ser servido descascado e fatiado, pois do contrário seu consumo apresentar-se-á como inconveniente. 
A procura por alimentos saudáveis tem aumentado a cada dia. Porém, o tempo disponível para o preparo dos alimentos tem sido reduzido devido à vida agitada nas cidades. Frutas e hortaliças minimamente processadas mantêm a qualidade do produto fresco, além de possuir grande facilidade para o seu preparo e consumo, que é a sua maior vantagem em comparação com outros.

$\mathrm{O}$ teor de vitamina $\mathrm{C}$ (ácido ascórbico) pode variar de 30 a $110 \mathrm{mg} / 100 \mathrm{~g}$ de fruto, dependendo da cultivar, maturidade, época do ano e o método de determinação deste ácido (Matsumoto et al., 1983; Cotter et al., 1991).

A cultivar Hayward do kiwi é a mais empregada nos principais países produtores, e seus frutos, densamente cobertos por pêlos finos e sedosos, apresentam cor marrom-claro. Possuem maior resistência a baixas temperaturas na frigoconservação do que as das demais cultivares, sendo possível sua armazenagem por um período superior a oito meses (Schuck, 1992).

Em frutos e hortaliças minimamente processados, ocorrem vários tipos de reações oxidativas que causam escurecimento, descoloração de pigmentos endógenos, perda ou mudanças do sabor ou do odor, mudanças na textura, e perda nutricional (Wiley, 1994).

O ácido ascórbico e seus vários sais neutros e outros derivados são os principais antioxidantes usados em frutos, hortaliças e seus sucos, para prevenir escurecimento e outras reações oxidativas. Além de ser totalmente seguro para o consumo humano, pode aumentar o teor de vitamina $\mathrm{C}$ de certos frutos e hortaliças (Préstamo \& Manzano, 1993; Wiley, 1994).

Além de antioxidante, o ácido cítrico também é um agente quelante, e é usado sinergisticamente com os ácidos ascórbico ou eritórbico e seus sais neutros para quelar pro-oxidantes, os quais podem causar rancidez, e para inativar enzimas como a polifenoloxidase que causa reações de escurecimento (Wiley, 1994).

A influência da aplicação de Ca em frutos tem recebido considerável atenção, visto que este nutriente produz efeitos desejáveis, retardando a maturação e a senescência, e controlando desordens fisiológicas em frutos e hortaliças. Ele tem um papel especial na manutenção da estrutura da parede celular em frutos, pois interage com a pectina desta parede formando pectato de $\mathrm{Ca}$, proporcionando uma textura mais firme aos frutos (Poovaiah, 1986). A presença de $\mathrm{Ca}$, além de conferir insolubilidade ao material péctico, limita a ação da enzima poligalacturonase, uma vez que o pectato de Ca formado é resistente à degradação por esta enzima. $\mathrm{O}$ tratamento com Ca também pode ser benéfico para produtos minimamente processados, pois esse tratamento mantém a firmeza de morangos fatiados melhor do que em morangos inteiros (Morris et al., 1985).

Este trabalho teve por objetivo avaliar a qualidade de kiwis minimamente processados, tratados com ácido ascórbico, ácido cítrico e cloreto de cálcio, durante o armazenamento sob refrigeração.

\section{Material e Métodos}

Foram utilizados kiwis, cultivar Hayward, adquiridos no comércio de Lavras, $\mathrm{MG}$, oriundos da Itália. Os frutos sofreram desinfecção em água gelada $\left(8^{\circ} \mathrm{C}\right) \mathrm{com} 100 \mathrm{mg} / \mathrm{L}$ de hipoclorito de sódio, por cinco minutos, sendo em seguida submetidos ao descascamento, utilizando-se facas afiadas, e fatiamento no sentido transversal, através de um cortador portátil. As fatias apresentavam uma espessura aproximada de $1 \mathrm{~cm}$. As etapas de descascamento e fatiamento foram realizadas em ambiente a $23^{\circ} \mathrm{C}$. Logo após, os frutos fatiados foram levados para câmara fria a $10^{\circ} \mathrm{C}$, onde foram imersos, por três minutos, nas soluções que corresponderam aos tratamentos de imersão em água pura (controle), imersão em solução de cloreto de Ca a $1 \%$, imersão em solução de ácido ascórbico a $1 \%$, imersão em solução de ácido cítrico a $1 \%$. As fatias dos frutos foram colocadas sobre uma mesa para escorrer o excesso de líquido por quatro minutos. Em seguida foram acondicionadas em embalagens de polietileno teraftalato com $23,5 \mathrm{~cm}$ de comprimento, $17,0 \mathrm{~cm}$ de largura e $7,5 \mathrm{~cm}$ de altura e armazenadas em câmara fria a $1 \pm 0,5^{\circ} \mathrm{C}$ e $85 \pm 3 \%$ de UR por um período de 10 dias. Análises de perda de massa, açúcares solúveis totais, conteúdo de ácido ascórbico e pectinas foram realizadas a cada dois dias.

A perda de massa foi determinada através de pesagem em balança semi-analítica, com os resultados expressos em porcentagem, considerando-se a diferença entre o peso inicial da fatia e aquele obtido a cada intervalo de tempo de amostragem.

Os açúcares solúveis totais foram extraídos com álcool etílico a $80 \%$ e determinados pelo método de Antrona 
(Dische, 1962). Os resultados foram expressos em $\mathrm{g}$ de glucose por $100 \mathrm{~g}$ de polpa.

O conteúdo de ácido ascórbico (após a oxidação a ácido deidroascórbico) foi determinado pelo método colorimétrico com 2,4 dinitrofenilidrazina, segundo Strohecker \& Henning (1967). A leitura foi realizada em espectrofotômetro Beckman 640 B, com sistema computadorizado. Os resultados foram expressos em mg/100 g de polpa.

As pectinas, total e solúvel, foram extraídas conforme McCready \& McComb (1952) e determinadas colorimetricamente segundo Bitter \& Muir (1962), sendo os resultados expressos em mg de pectina por $100 \mathrm{~g}$ de polpa.

Durante o período de armazenamento, foram coletadas assepticamente, amostras de $50 \mathrm{~g}$ para as análises microbiológicas realizadas segundo Vanderzant \& Splittstoesser (1992). As amostras foram diluídas em água estéril peptonada a $0,1 \%$ e após serem submetidas às diluições seriadas foram inoculadas nos diferentes meios de cultura utilizados no experimento. Foram efetuadas análises de microrganismos aeróbios, bolores e leveduras e de coliformes totais e fecais.

Na contagem total de microrganismos aeróbios mesófilos e psicrotróficos utilizou-se o meio "Plate Count Agar". As amostras, em duplicata, diluídas a $10^{-1}, 10^{-2}$ e $10^{-3}$ foram inoculadas neste meio e incubadas a $32^{\circ} \mathrm{C}$ por 48 horas para a contagem de mesófilos e a $5-7^{\circ} \mathrm{C}$ por sete dias, para a contagem de psicrotróficos.

A contagem total de bolores e leveduras foi realizada em meio Batata Dextrose Ágar (BDA) acidificado com ácido tartárico a 3,5\%, que, após a inoculação das amostras, foi incubado a $25^{\circ} \mathrm{C}$ por $3-5$ dias.

O meio de cultura Lauryl Sulfato Triptose (LST) foi utilizado para a inoculação das amostras, para análise de coliformes em série de três tubos, contendo tubo de Durhan invertido, que foram incubados a $35-37^{\circ} \mathrm{C}$, por 48 horas. Após as leituras, foram feitos os cálculos do número de coliformes fecais e totais utilizando-se a tabela do número mais provável (NMP) por grama de amostra.

O experimento foi conduzido em delineamento inteiramente casualizado, composto de quatro tratamentos (controle, cloreto de cálcio, ácido ascórbico, ácido cítrico) e seis períodos de armazenamento (0, 2, 4, 6, 8 e 10 dias), compondo um fatorial $4 \times 6$, com três repetições. Cada unidade experimental constou de 16 fatias.

\section{Resultados e Discussão}

Em relação à perda de massa, houve efeito significativo do período de armazenamento $(\mathrm{p}<0,01)$ e dos diferentes tratamentos $(\mathrm{p}<0,01)$, embora não tenha sido observada interação significativa entre esses dois fatores $(p>0,05)$. Houve aumento na perda de massa durante o período experimental, embora a mesma não tenha chegado a 1\% (Figura 1). Essa perda mínima pode ser atribuída ao uso da embalagem, que restringe as trocas gasosas do fruto com o meio, criando uma atmosfera modificada em seu interior.

As fatias de frutas tratadas e não tratadas com ácido ascórbico apresentaram a maior e a menor perda de massa, respectivamente (Figura 2). As fatias tratadas com cloreto de cálcio e ácido cítrico não apresentaram diferenças significativas entre si quanto à perda de massa.

A perda de massa é um dos principais fatores na vida de armazenamento de muitos produtos

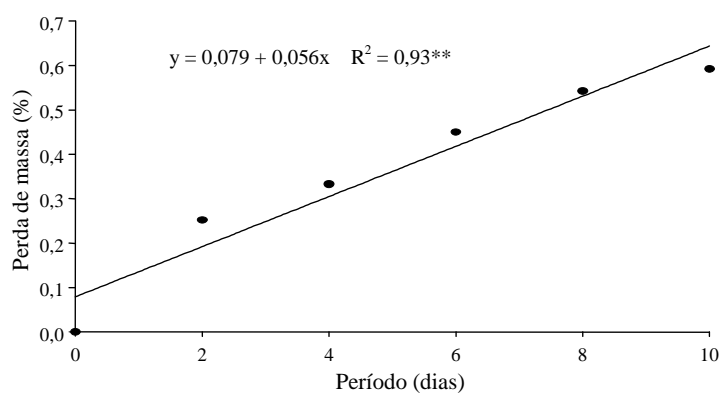

Figura 1. Perda de massa de kiwis (y) minimamente processados e armazenados sob condições refrigeradas $\left(1^{\circ} \mathrm{C}\right.$, $85 \%$ de UR), durante 10 dias (x). ${ }^{*}$ Significativo a $1 \%$ de probabilidade.

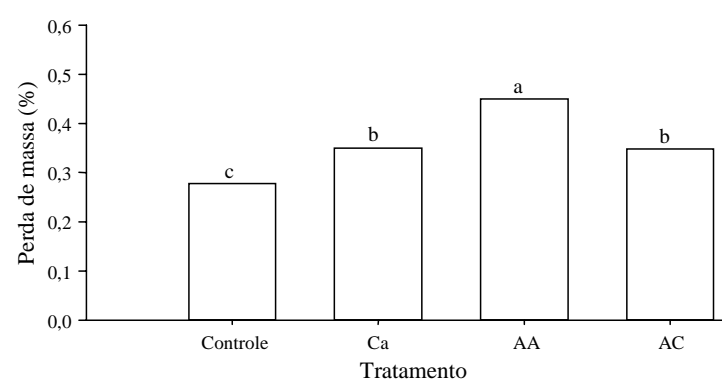

Figura 2. Valores médios de perda de massa de kiwis minimamente processados submetidos a tratamentos em soluções a 1\% de cloreto de cálcio (Ca), ácido ascórbico (AA) e ácido cítrico (AC) e à água (controle) após 10 dias de armazenamento sob condições refrigeradas $\left(1^{\circ} \mathrm{C}, 85 \%\right.$ de UR). Letras diferentes sobre as barras indicam diferença entre os tratamentos pelo teste de Tukey a $5 \%$ de probabilidade. 
hortícolas. Ela ocorre em razão do tempo de armazenamento e da transpiração. Essa perda tem efeitos marcantes sobre a fisiologia dos tecidos vegetais e, em alguns casos, antecipa a maturação e a senescência de frutos tropicais (Yang \& Hoffmann, 1984). A perda de massa se relaciona à perda de água, causa principal da deterioração, resultando não somente em perdas quantitativas, mas também na aparência (murchamento e enrugamento), nas qualidades texturais (amaciamento, perda de frescor e suculência) e na qualidade nutricional (Kader, 1992).

A análise estatística detectou efeito significativo da interação entre os tratamentos e o período de armazenamento $(p<0,01)$ com relação ao conteúdo de açúcares solúveis totais. Houve uma ligeira redução nos teores de açúcar com o tempo de armazenamento (Figura 3). Porém, nas fatias do controle e naquelas tratadas com cloreto de cálcio, houve uma queda ligeiramente acentuada nos dois primeiros dias de armazenamento. Após esse período, observou-se uma tendência de estabilização nos teores de açúcar, indicando que o produto atingiu o equilíbrio. Essa redução nos teores de açúcares pode ser explicada pelo aumento na taxa respiratória dos frutos. A ação física do processamento mínimo induz à produção de etileno, denominado etileno de ferimento e também induz a uma elevação na respiração, respiração de ferimento, a qual utilizará rapidamente os substratos de reserva (Watada et al., 1990). Nos frutos fatiados tratados com ácido ascórbico e ácido cítrico não foi observada nenhuma queda acentuada nos teores de açúcares, o que, provavelmente, é explicado pelo fornecimento de ácidos para esses frutos, através dos tratamentos, os quais podem ser substratos respiráveis. Assim, no início do armazenamento, quando o fruto tendeu a aumentar sua taxa respiratória devido ao estresse promovido pelo corte, os ácidos fornecidos pelos dois tratamentos possivelmente podem ter servido de substratos para a respiração. Os valores encontrados para açúcar total estão próximos aos citados por Reid et al. (1982) e Matsumoto et al. (1983), que encontraram, no kiwi, valores médios de $9,47 \%$ e $8,25 \%$, respectivamente.
Houve efeito significativo da interação tratamentos e período de armazenamento sobre os teores de ácido ascórbico $(\mathrm{p}<0,01)$, pois as fatias tratadas com este ácido apresentaram teores mais elevados do mesmo quando comparados aos demais tratamentos, o que indica que houve absorção do ácido ascórbico nas fatias tratadas com o mesmo. Em média, esse aumento foi cerca de $25 \%$.
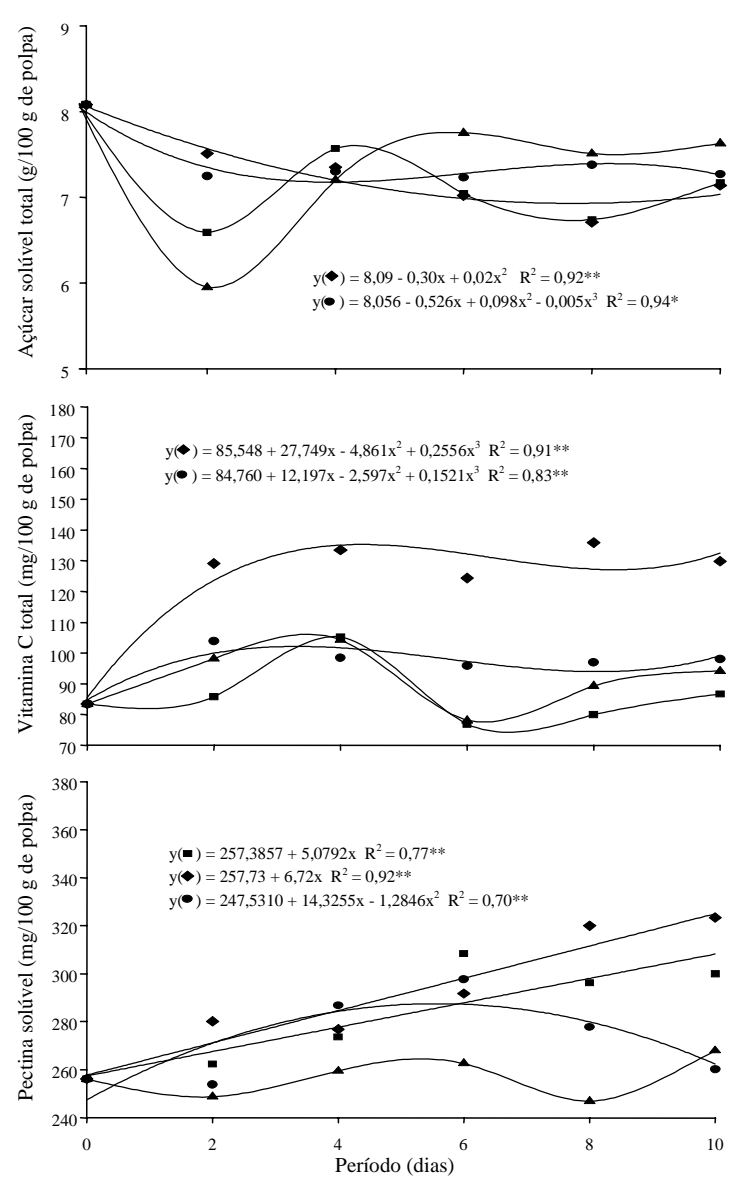

Figura 3. Açúcar solúvel total, vitamina $C$ total e pectina solúvel em kiwis minimamente processados submetidos a tratamentos em soluções a $1 \%$ de ácido ascórbico (•), áci-

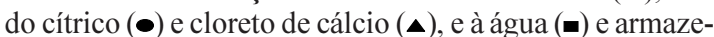
nados sob condições refrigeradas $\left(1^{\circ} \mathrm{C}, 85 \%\right.$ de UR), durante 10 dias. O controle (água) e o tratamento com cloreto de cálcio não tiveram efeito significativo no teor de açúcar solúvel total e no teor de vitamina $\mathrm{C}$ total. $\mathrm{O}$ tratamento com cloreto de cálcio não teve efeito significativo no teor de pectina solúvel. 
O aumento observado nos teores de ácido ascórbico nos dois primeiros dias de armazenamento deveu-se ao fato de que no tempo zero dias todos os frutos foram considerados controle, pois não receberam nenhum tratamento. Quanto aos demais tratamentos, as diferenças entre eles foram mínimas, e esses teores variaram ligeiramente durante o período de armazenamento (Figura 3).

Os valores encontrados para vitamina $\mathrm{C}$ estão próximos aos valores encontrados por Okuse \& Ryugo (1981), cerca de $80 \mathrm{mg}$ de ácido ascórbico/ $100 \mathrm{~g}$ de polpa. Estes valores aparentemente não foram afetados pelo processamento mínimo. Segundo esses autores, as células de kiwi acumulam numerosas ráfides de oxalato de $\mathrm{Ca}$, proporcionando efeito tampão e impedindo que o ácido ascórbico se oxide, contribuindo para a estabilidade de ácido ascórbico no fruto.

Não houve efeito dos tratamentos nem do período de armazenamento $(\mathrm{p}>0,05)$ sobre o teor de pectina total sendo o valor médio encontrado de $618,47 \mathrm{mg} / 100 \mathrm{~g}$ de polpa. Menezes (1996), trabalhando com melões, também não observou nenhuma diferença significativa nos níveis de pectina total durante a maturação.

Quanto ao teor de pectina solúvel, houve efeito significativo da interação tratamento e período de armazenamento $(p<0,01)$. As fatias tratadas com ácido ascórbico apresentaram os maiores teores de pectina solúvel ao longo do tempo, indicando, assim, que encontravam-se mais amolecidas. Este resultado está de acordo com Gil et al. (1998), que, estudando maçãs 'Fuji' fatiadas e tratadas com $2 \%$ de ácido ascórbico, observaram que este tratamento aumentou-lhes a vida-de-prateleira somente por um curto período de tempo, uma vez que o ácido ascórbico amolece os tecidos dos frutos. O tratamento com cloreto de cálcio tendeu a apresentar os menores valores para pectina solúvel (Figura 3). Esta constatação está de acordo com Gonçalves (1998), que também observou menores teores de pectina solúvel em abacaxis tratados com cloreto de cálcio.

A solubilização de substâncias pécticas é uma tendência natural durante o amadurecimento dos frutos, sendo que o Ca pode contribuir para a estabilização da parede celular, através da formação de pectatos de $\mathrm{Ca}$, auxiliando, dessa forma, na redução da solubilização péctica e na manutenção da firmeza do fruto (Poovaiah, 1986; Salunke et al., 1991). Os íons $\mathrm{Ca}^{2+}$ agem, provavelmente, como pontes iônicas entre resíduos de ácido galacturônico carregados negativamente, formando uma estrutura estável denominada "egg box" (Brett \& Waldron, 1990).

A comprovada influência do $\mathrm{Ca}$ em reduzir a solubilização de substâncias pécticas leva a inferir em uma menor perda de firmeza da polpa nos frutos tratados com cloreto de cálcio, uma vez que as pectinas contribuem em grande parte para a manutenção desse atributo de qualidade.

Não se detectaram coliformes totais e fecais e mesófilos, durante o período de armazenamento. Em relação ao grupo bolores e leveduras, foi observado, no período de 10 dias, que os frutos tratados com ácido cítrico apresentaram uma leve alteração com valores mínimo e máximo de $<30$ e $4,9 \times 10^{2} \mathrm{UFC} / \mathrm{g}$, respectivamente. $\mathrm{Na}$ contagem de psicrotróficos também constatou-se uma leve alteração aos oito dias em frutos tratados com ácido cítrico $(<30 \mathrm{a}$ $3,6 \times 10^{3} \mathrm{UFC} / \mathrm{g}$ ). O'Connor-Shaw et al. (1994), trabalhando com kiwis minimamente processados e armazenados a $4^{\circ} \mathrm{C}$ por quatro dias, também encontraram valores próximos em relação a bolores e leveduras. Os autores relatam que o crescimento microbiano parece não contribuir para a deterioração de kiwis fatiados. Quanto a frutos e hortaliças minimamente processados, ainda não existe legislação com os limites de contagens tolerados. Existe legislação para frutas frescas, inteiras refrigeradas ou congeladas, consumidas diretamente que estipula o limite somente para coliformes fecais, que é de $2 \times 10^{2} / \mathrm{g}$. Em relação aos demais grupos microbianos nada consta na legislação vigente.

Os baixos níveis de contaminação microbiana encontrados neste trabalho são devidos à desinfecção com hipoclorito de sódio (200 mg/L) feita em todos os equipamentos utilizados, e nas embalagens. As pessoas que realizaram as operações de processamento usaram luvas, gorro, máscara e avental durante todo o processo. Produtos minimamen- 
te processados ficam expostos a qualquer tipo de contaminação, uma vez que a casca que funcionava como uma barreira à penetração de microrganismos é descartada. Assim, em frutos e hortaliças submetidos ao processamento mínimo, as condições de processamento devem ser extremamente higiênicas, tomando-se os devidos cuidados em cada etapa.

\section{Conclusões}

1. O cálcio, fornecido pelo cloreto de cálcio, é absorvido pelos tecidos, indicando menor solubilização da pectina, nos frutos submetidos a esse tratamento.

2. O tratamento com ácido ascórbico aumenta o teor de vitamina $\mathrm{C}$ total de kiwis fatiados.

3. Em condições satisfatórias de limpeza, kiwis minimamente processados apresentam contaminação microbiológica baixa ou ausente.

4. O uso de ácido ascórbico ou cítrico não possui efeito na manutenção da qualidade de kiwis minimamente processados.

5. O uso de solução de cloreto de cálcio a $1 \%$ mantém a qualidade de kiwis minimamente processados por até 10 dias, se armazenados a $1{ }^{\circ} \mathrm{C}$ e $85 \%$ de UR.

\section{Referências}

BITTER, T.; MUIR, H. M. A modified uronic acid carbazole reaction. Analytical Biochemistry, New York, v. 34 , p. $330-334,1962$

BRETT, C.; WALDRON, K. Physiology and biochemistry of plant cell wall. London: Hyman, 1990. $194 \mathrm{p}$.

COTTER, R. L.; MacRAE, E. A.; FERGUSON, A. R.; McMATH, K. L.; BRENNAN, C. J. A comparison of the ripening, storage and sensory qualities of seven cultivars of kiwifruit. Journal of Horticultural Science, Ashford, v. 66, n. 3, p. 291-300, May/Apr. 1991

DISCHE, E. Color reactions of carbohydrates. In: WHISTLER, R. L.; WOLFRAM, M. L. (Ed.). Methods in carbohydrates chemistry. New York: Academic, 1962. v. 1 , p. $477-512$

GIL, M. I.; GORNY, J. R.; KADER, A. A. Responses of 'Fuji' apple slices to ascorbic acid treatments and low-oxygen atmospheres. HortScience, Alexandria, v. 33, n. 2, p. 305-309, Apr. 1998.
GONÇALVES, N. B. Efeito da aplicação de cloreto de cálcio associado ao tratamento hidrotérmico sobre a composição química e suscetibilidade ao escurecimento interno do abacaxi cv. Smooth Cayenne. 1998 $101 \mathrm{f}$. Tese (Doutorado) - Universidade Federal de Lavras, Lavras.

KADER, A. A. Postharvest technology of horticultural crops. Davis: University of California, 1992. 296 p.

McCREADY, P. M.; McCOMB, E. A. Extraction and determination of total pectic material. Analytical Chemistry, Washington, v. 24, n. 12, p. 1586-1588, Dec. 1952.

MATSUMOTO, S.; OBARA, T.; LUH, B. S. Changes in chemical constituents of kiwifruit during post-harvest ripening. Journal of Food Science, Chicago, v. 48, p. 607-611, Mar./Apr. 1983.

MENEZES, J. B. Qualidade pós-colheita de melão tipo Galia durante a maturação e o armazenamento. 1996. 157 f. Tese (Doutorado) - Universidade Federal de Lavras, Lavras.

MORRIS, J. R.; SISTRUNK, W. A.; SIMS, C. A.; MAIN, G. L. Effects of cultivar, postharvest storage, preprocessing dip treatments and style of pack on the processing quality of strawberries. Journal of the American Society for Horticultural Science, Alexandria, v. 110, n. 2, p. 172-177, Mar. 1985.

O'CONNOR-SHAW, R. E.; ROBERTS, R.; FORD, A. L.; NOTTINGHAM, S. M. Shelf life of minimally processed honeydew, kiwifruit, papaya, pineapple and cantaloupe. Journal of Food Science, Chicago, v. 59, n. 6, p. 1202-1206, Nov./Dec. 1994.

OKUSE, I.; RYUGO, K. Compositional changes in the developing 'Hayward' kiwifruit in California. Journal of the American Society for Horticultural Science. Alexandria, v. 106, n. 1, p. 73-76, Jan./Feb. 1981.

POOVAIAH, B. W. Role of calcium in prolonging storage life of fruits and vegetables. Food Technology, Chicago, v. 16, n. 1, p. 86-89, Jan. 1986.

PRÉSTAMO, G.; MANZANO, P. Peroxidases of selected fruits and vegetables and the possible use of ascorbic acid as an antioxidant. HortScience, Alexandria, v. 28, n. 1, p. 48-50, Jan. 1993.

REID, M. S.; HEATHERBELL, D. A.; PRATT, H. K. Seasonal patterns in chemical composition of the fruit of Actinidia chinensis. Journal of the American Society 
for Horticultural Science, Alexandria, v. 107, n. 2, p. 316-319, Mar. 1982.

SALUNKE, D. K.; BOLIN, H. R.; REDDY, N. R. Storage processing and nutritional quality of fruits and vegetables: fresh fruits and vegetables. 2. ed. Boca Raton: CRC, 1991. v. 1.

SCHUCK, E. Cultivares de quivi. Agropecuária Catarinense, Florianópolis, v. 5, n. 4, p. 9-12, out./dez. 1992.

STROHECKER, R. L.; HENNING, H. M. Análisis de vitaminas: métodos comprobados. Madrid: Paz Montalvo, 1967. $428 \mathrm{p}$
VANDERZANT, C.; SPLITTSTOESSER, D. F. Compendium of methods for the microbiological examination of foods. 3. ed. Washington: American Public Health Association, 1992. 1919 p.

WATADA, A. E.; ABE, K.; YAMUCHI, N. Physiological activities of partially processed fruits and vegetables. Food Technology, Chicago, v. 44, n. 5, p. 116-122, May 1990. WILEY, R. C. Minimally processed refrigerated fruits and vegetables. New York: Chapman \& Hall, 1994. 368 p.

YANG, S. F.; HOFFMANN, N. E. Ethylene biosynthesis and its regulation in higher plants. Annual Review of Plant Physiology, Palo Alto, v. 35, p. 155-189, 1984. 